\title{
Analytical study on creep shear failures of RC slender beams without web reinforcement
}

\author{
Halwan Alfisa Saifullah ${ }^{1,2}$, Kenichiro Nakarai ${ }^{1,{ }^{*}}$, Nobuhiro Chijiwa ${ }^{3}$, and Koichi Maekawa ${ }^{4}$ \\ ${ }^{1}$ Department of Civil and Environmental Engineering, Hiroshima University, Hiroshima, Japan \\ ${ }^{2}$ Department of Civil Engineering, Universitas Sebelas Maret, Surakarta, Indonesia \\ ${ }^{3}$ Department of Civil Engineering, Tokyo Institute of Technology, Tokyo, Japan \\ ${ }^{4}$ Department of Urban Innovation, Yokohama National University, Yokohama, Japan
}

\begin{abstract}
Sustained load problems, which can cause excessive deformation and severe damage to concrete structures, have been considered in current worldwide design codes by applying reduction factors on the compressive and tensile strength of concrete. A reduction factor in the shear design may also be required due to the decrease of shear-transfer action corresponding to the increases of the shear cracks opening. However, only a few studies are examining the effect of creep on shear performance of concrete structures, and the results are still inconclusive. As a complement to the previous experimental works, this study aims to investigate the effect of loading rate on the shear capacity of $\mathrm{RC}$ slender beams by non-linear finite element (FE) analysis. A spaceaveraged constitutive model with fixed multi-directional cracks was employed in the simulation of diagonal shear failure. The present study analytically examines the time-dependent effects on the beams under different loading rates until the delayed failure and compares the results with the previous experimental ones.
\end{abstract}

\section{Introduction}

Sustained load, which is practically experienced by every single structure, has received much attention in recent decades due to its severe effects. Depending on the duration of the sustained load and load intensity, nonlinear creep strain and micro-cracks can be potentially developed causing damage to the internal structure and reduction of concrete uniaxial compressive strength [1-4]. On the other hand, the basic creep created in tension is much lower than that of creating in compression; hence it is usually ignored in design [5]. In reinforced concrete (RC) structures, excessive deformation problems due to sustained load appear to be more dominant than direct reduction in bending capacity [6,7]. Plastic deformation was reported as being several times larger than the elastic deformation $[8,9]$. The existing cracks become wider under long-term loading [10] and make structures more vulnerable to aggressive environmental attacks.

Although many researchers on sustained load have been reported over the last decades, only some of them examined the effects on shear performance of RC structures. Time-

*Corresponding author: nakarai@hiroshima-u.ac.jp 
dependent shear transfer models were generally proposed based on an assumption that the contribution of all shear-transfer action decreases for increasing openings of the critical shear cracks due to sustained load [11]. However, some experimental works indicated that there is no significant effect of sustained load on shear performance of RC slender beams (the ratio between shear span $a$ to effective depth $d$ is between 2.5 and 6.5). Sarkosh et al. $[12,13]$ investigated the behaviour of RC slender beams under a high load intensity within a duration of up to 1113 days. The beams deformed due to creep and some cracks opened over a period. No reduction of the shear strength was reported at the end of the long-term loading. The previous study by the authors [14] confirmed these findings based on a test of RC slender beams loaded under different loading rates. The mid-span deflection, compressive strain of concrete at the top surface of the beams, and total flexural crack width during the loading test tended to increase with an increase in the loading duration. Nevertheless, the diagonal cracking strength of the beams was almost constant under different loading rates, and the ultimate strength under the slower loading rates exhibited higher values when compared to those under the normal loading rate. The time-dependent effect on the shear capacity of RC beams seemed to be more pronounced with decreasing ratios of shear span to effective depth of the beams $(a / d<2.5)[15,16]$.

The present study applies a nonlinear finite element (FE) analysis to analyse the experimental work by the authors on shear performances of RC slender beams under different loading rates. A possible increase in fracture energy of concrete under slower loading rates and its contribution to the shear resistance of the beams is examined through sensitivity analysis.

\section{Numerical simulation}

A space-averaged time-dependent constitutive model with fixed multi-directional cracks is used to simulate the shear performance of RC slender beams under different loading rates by finite element method. In this approach, the reinforcement bar and cracks are being distributed over the whole element; and the reinforced concrete (RC) element carries the summation of the average stresses of the cracked concrete and the reinforcement bar [17]. All constitutive models (including compression, tension, and shear transfer models with the time dependency) are coded in computational framework, DuCOM-COM3, and its applicability has been successfully verified with various experiments [18].

The shear performance of RC slender beams under different loading rates is numerically simulated referring to the experimental work conducted by the authors [14]. The beam had a ratio of shear span $a$ to effective depth $d$ of 3.0 and was designed to fail in shear tension failure before the yielding of the tension reinforcement. Hence, high-strength deformedsteel reinforcements $\left(f_{y}=1062 \mathrm{MPa}\right)$ with a tension reinforcement ratio of $0.8 \%$ were used. The details of the beam can be seen in Fig.1. In the numerical modelling, the entire concrete of the RC beam can be divided into a plain concrete zone (PL) and a reinforced concrete (RC) zone. The RC zone represents the behaviour of concrete surrounding the reinforcements which exhibits a tension/shear-stiffening behaviour. Meanwhile, the remaining concrete can be represented by the PL zone which exhibits a tension/shear softening behaviour. 


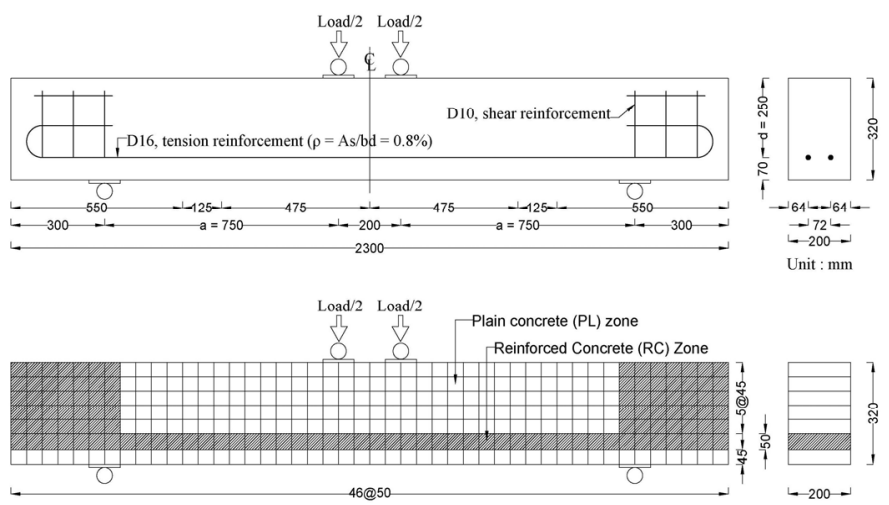

Fig. 1. Outlines of RC slender beam: experimental setup [14] (top); zoning method in numerical modelling (bottom).

Considering the tension stiffening and softening behaviour of concrete after cracking, the tension stiffening/softening parameter $c$ was applied. For the RC zone with an ordinary deformed bar, the coefficient of tension stiffening/softening can be set 0.4 as a recommended value [17]. On the other hand, the softening parameter for the PL zone is determined based on the fracture energy balance and the size of the finite element $[19,20]$ as indicated by equation (1). Due to the absence of experimental data, the fracture energy of concrete is estimated based on the CEB-FIP 2010 model [21]. Fig.2 shows the normalised tensile stress-strain curves adjusted based on the reference lengths of the finite elements.

$$
\int f_{t}\left(\frac{\varepsilon_{t u}}{\varepsilon_{t}}\right)^{c}=\frac{G_{f}}{l_{r}} \quad G_{f}=73 f_{c}^{\prime 0.18}
$$

Where $G_{f}$ is the fracture energy of concrete $(\mathrm{N} / \mathrm{m}) ; f_{c}^{\prime}$ is compressive strength of concrete; $\varepsilon_{t u}$ is the crack strain defined equal to $2 f_{t} / E_{o} ; E_{o}$ is the initial stiffness of concrete; $l_{r}$ is the reference length of the finite element in which the average softening stress-strain relation is defined.

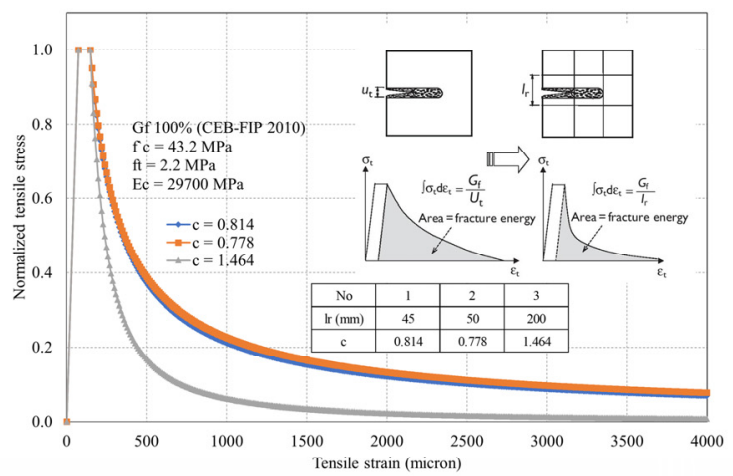

Fig. 2. Numerical modelling of RC slender beam: tension softening curves.

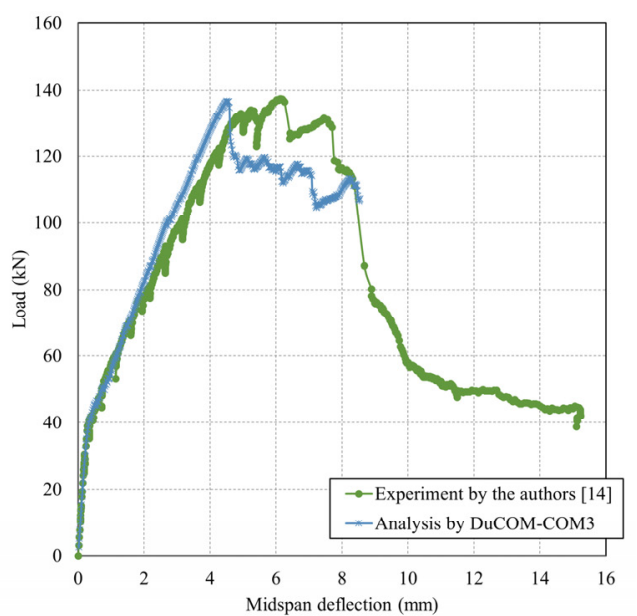

Fig. 3. Verification of simulation with experiment. 
The experimental compressive strength and elastic modulus of concrete were 43.2 $\mathrm{MPa}$ and $29.7 \mathrm{GPa}$, respectively. These values were used in the simulation to maintain the consistency of the referred case. The structural tensile strength of concrete was estimated around 2.2 MPa obtained from an inverse analysis of the flexural cracking strength of the $\mathrm{RC}$ beam. Then, a displacement rate of $10 \mathrm{~mm} / \mathrm{hr}$ was applied as a static or normal loading rate. The numerical analysis results showed that the diagonal cracking strength and ultimate strength of RC beams occurred at the same time as shown in Fig.3. Theoretically, this can be accepted because the ultimate load often occurs just after the diagonal cracking strength is exceeded in the case of RC slender beams $(2.5<\mathrm{a} / \mathrm{d}<6.5)$ [22]. The numerical model of the beam failed in shear with a $0.6 \%$ difference of ultimate experimental load. This indicated that the numerical modelling was reliable in reproducing the shear failures of RC slender beams.

\section{Behaviour of RC beam under different loading rates}

In the previous experimental study by the authors [14], loading rates of 100 and 1000 times slower than the normal loading rate $(10 \mathrm{~mm} / \mathrm{hr})$ were selected to represent slow loading and very slow loading. The corresponding strain rate induced in the reinforcement bars under the normal and slower loading rates fell in the range of static to creep regime, respectively [23]. Although the creep effects were revealed in the experiment, the diagonal cracking strengths were almost constant (a decrease of only 1 percent) under the slow loading rate and a slight increase (an increase of only 5\%) was found under the very slow loading rate. Additionally, the RC beams loaded under the normal loading rate and slow loading rate displayed almost identical ultimate strengths (an increase of only 5\%) and increased (an increase of $16 \%$ ) in the case of the very slow loading rate.
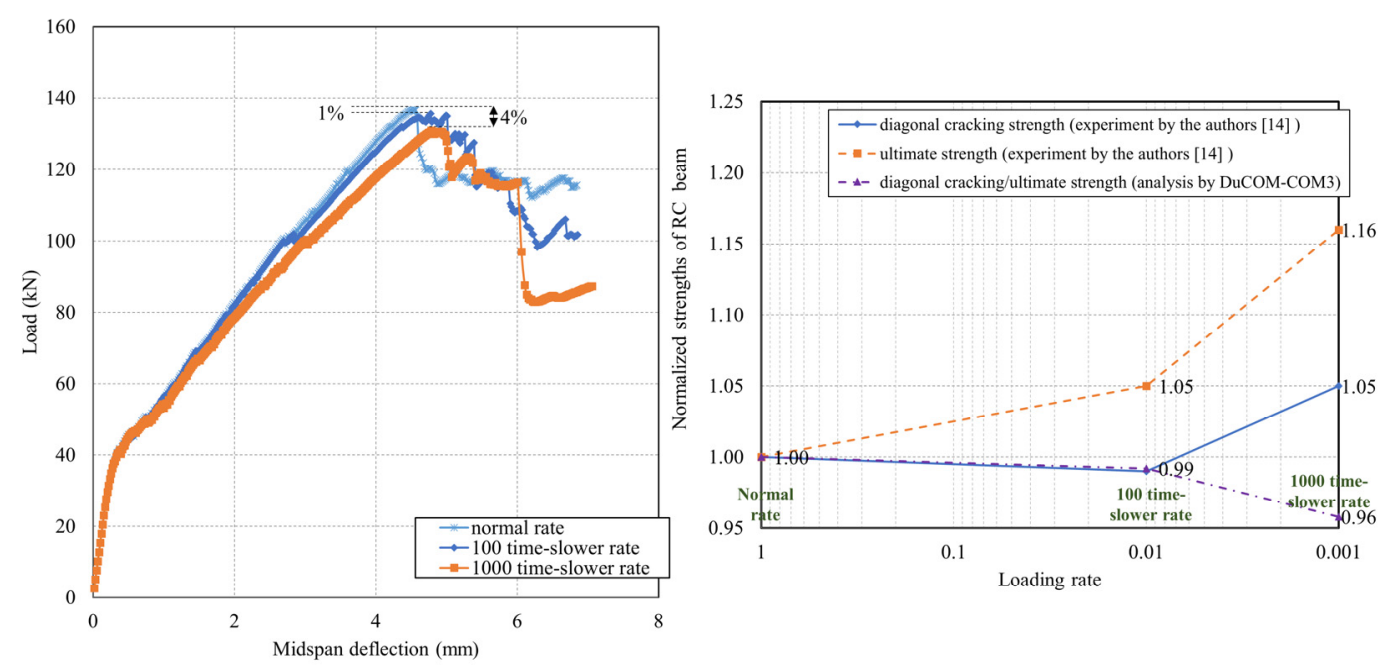

Fig. 4. RC slender beam under different loading rates: load-midspan deflection of the beams (left); comparison between the analytical and experimental strengths of the beams (right).

As can be seen from Fig.4, the slope of the load-midspan deflection relationship of the beams under slower loading rates was flatter than those under the normal one. This is because a larger increase in the compressive strain due to creep resulted in a larger bending deformation and a wider flexural crack width. The much wider flexural crack width can generally decrease the contribution of the aggregate interlocking to the total shear capacity of the RC beam. The reductions of the ultimate strength of the beams under the 100 and 
1000 times slower rates are $1 \%$ and $4 \%$, respectively. Using the same computational framework, Bugalia et al. [16] conducted an analytical study of RC beams with varied parameters, such as the ratio between the shear span to the effective depth $(\mathrm{a} / \mathrm{d})$ under sustained load. The RC slender beam $(\mathrm{a} / \mathrm{d}=2.41$ in their study $)$ was estimated to possess an almost time-independent capacity within a general design period (100 years). It is noted that the ultimate strength for a given period is lower in the case of different loading rates compared to those under sustained load [2]. Since the primary mode of RC slender beams is tension-shear failure, and the magnitude of the tension time-dependency is much less than that of in compression, there are insignificant effects of both slower loading rates and sustained load on the shear capacity of RC slender beams.

\section{Possibility of the increased shear strength of RC beam under slower loading rates}

The comparison between the experimental and analytical results was also presented in Fig. 4. Although under the slower loading rates the diagonal cracking/ultimate strength in the numerical analysis decreased insignificantly, the behaviour of the beams had a different tendency to the experiment results. In the case of the slower loading rates, the internal stresses around the significant inclined cracking of the RC beams were better redistributed according to the experimental observation by the authors [14]. This was indicated by the more parallel-branched cracks that occurred around the inclined cracking, providing more shear transfer interface (since a significant difference on the shear critical opening was not observed). This phenomenon might increase the aggregate interlock that contributed to the shear capacity of the beams and compensated the adverse effect caused by the creep of concrete. In the experiment conducted by Sarkosh $[12,13]$, the shear capacity of the beams was also reported increasing by $8 \%$ at the end of long-term sustained loads.

Fracture energy of concrete is an important parameter affecting the shear strength of RC beams. As RC slender beams fail in a tension-shear failure mode, their behaviour is not only mainly controlled by the tensile strength of concrete but also by the energy required to generate a crack. For the normal strength of concrete, the aggregate interlocking is also strongly related to fracture energy. Initial investigation of the effect of loading rates on the fracture energy of concrete has been done by Wittman [24]. Under a wide range of loading rates (from $10^{-3}$ to $10 \mathrm{~mm} / \mathrm{min}$ ), the fracture energy became minimum at an intermediate rate $\left(10^{-2} \mathrm{~mm} / \mathrm{min}\right)$ and tended to increase as the loading rates increased as well as decreased. Subsequently, Zhou [25] reported that fracture energy seemed to decrease as rates became slower in his study (with varying rates from $3 \times 10^{-3}$ to $3 \mathrm{~mm} / \mathrm{min}$ ). The possibility of an increase in fracture energy under sustained load was indicated in the experimental study by Sarkosh et al. [13]. The shear safety margin became higher with the increasing fracture energy under sustained load. 


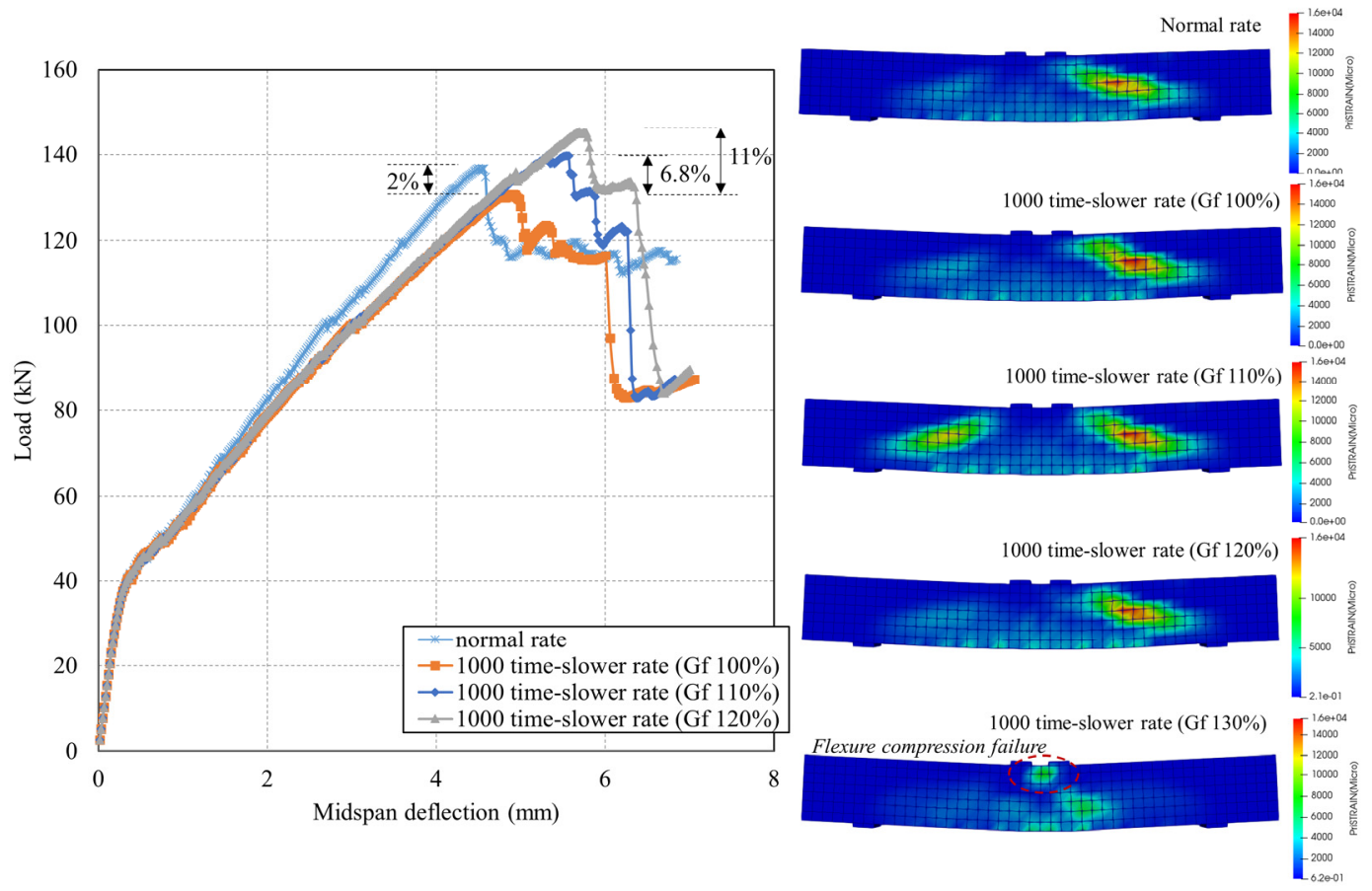

Fig. 5. The possible increased shear strengths of RC beams with increasing the fracture energy: loadmidspan deflection of the beams (left); failure modes (right).

The sensitivity analysis of the varying values of fracture energy on shear capacity of RC slender beams was conducted through this numerical analysis by adjusting the strainsoftening curve as exemplified in Fig. 2. Moreover, the correlation between the changing values of fracture energy and the ultimate strength of RC slender beams is presented in Fig.5. In the study by Wittman [24], the increase of fracture energy under a very slow loading rate is about $10-15 \%$. It is evidently observed that a $10 \%$ increase in fracture energy of concrete increased the ultimate strength of the beam by $6.8 \%$ and compensated the adverse effect of creep under slower loading rates in the simulation. A further increase in fracture energy could be done up to $20 \%$ with the improvement of the shear capacity of $11 \%$. The beams with $110 \%$ and $120 \%$ fracture energy failed in the same mode (a tensionshear failure) as those without any additions of fracture energy. The failure mode of the beams changed from the tension-shear failure to a flexural compression failure when the fracture energy was increased by more than $20 \%$, as also shown in Fig. 5 . This limitation was caused by the exceeded bending capacity of the beam by its shear capacity.

\section{Conclusion}

In the present study, the shear strength of RC slender beams under different loading rates was analytically evaluated by non-linear finite element analysis. The reliability and applicability of a space-averaged time-dependent constitutive model to simulate the failure of RC beams in shear was confirmed. Under slower loading rates, the shear capacity of the beams decreased because of creep in the simulation. However, this behaviour had a different tendency to the experiment results. The increasing of shear capacity of the beams in the experiments can be explained by a possible increase of fracture energy under different loading rates and sustained load. A $10 \%$ increase in fracture energy of concrete increased the shear strength of the beam and compensated the adverse effect of creep under 
slower loading rates. Future studies will consider a more comprehensive parametric analysis to obtain a better understanding of the effects of creep on the shear performance of RC beams.

The authors express their gratitude to Dr Satoshi Tsuchiya of Coms Engineering Corporation for his valuable advice in this analytical study. This research was supported financially by JSPS KAKENHI through Grant Numbers JP23226011.

\section{References}

1. W. H. Price. Journal Proceedings. Factors Influencing Concrete Strength. V 47-2, (1951)

2. H. Rusch. Journal Proceedings. Researches Toward a General Flexural Theory for Structural Concrete. V 57-7, (1960)

3. M.F. Ruiz, A. Muttoni, P.G. Gambarova. Journal of Advanced Concrete Technology. Relationship between Nonlinear Creep and Cracking of Concrete under Uniaxial Compression. V 5-3, 383-393 (2007)

4. D. Tasevski, M.F. Ruiz, A. Muttoni. CONCREEP 10. Analogy between Sustained Loading and Strain Rate Effects on the Nonlinear Creep Response of Concrete. (2015)

5. P. Rossi, J.L. Tailhan, F.L. Maou, L. Gaillet, E. Martin. Cement and Concrete Research. Basic Creep Cehaviour of Concretes Investigation of the Physical Mechanism by Using Acoustic Emission. V 42, 61-73 (2012)

6. A.M. Neville. The Journal of the N.Z. Non-elastic Deformations in Concrete Structures. V 12-4, 114-120 (1957)

7. A.M. Neville. IABSE Publications. Current Problems Regarding Concrete Under Sustained Loading. 337-343 (1966)

8. P.G. Fluck, G.W. Washa. Journal Proceedings. Creep of Plain and Reinforced Concrete. V 54-4 (1958)

9. J. Nie, C.S. Cai. Journal of Structural Engineering. Deflection of Cracked RC Beams under Sustained Loading. V126-6, 708-716 (2000)

10. W.C. Choi, H.D. Yun. Material \& Design. Long-term Deflection and Flexural Behavior of Reinforced Concrete Beams with Recycled Aggregate. V 51, 742-750 (2013)

11. M.F. Ruiz, A. Muttoni, J. Sagaseta. Engineering Structures. Shear Strength of Concrete Members without Transverse Reinforcement: A Mechanical Approach to Consistently Account for Size and Strain Effects. V 99, 360-372 (2015)

12. R. Sarkosh, J. Walraven, J.D. Uijl. The 36th Symposium of IABSE. Shear Capacity of Concrete Beams under Sustained Loading. (2013)

13. R. Sarkosh. Doctoral Thesis, TU Delft. Shear Resistance of Reinforced Concrete Beam without Shear Reinforcement under Sustained Loading. (2015)

14. H.A. Saifullah, K. Nakarai, V. Piseth, N. Chijiwa, K. Maekawa. ACI Structural Journal. Shear Creep Failures of Reinforced Concrete Slender Beams without Shear Reinforcement. V114-6, 1581-1590 (2017)

15. A. Somraj, K. Fujikake, B. Li. International Journal of Protective Structures. Influence of Loading Rate on Shear Capacity of Reinforced Concrete Beams. V 4-4, 521-543 (2013)

16. N. Bugalia, K. Maekawa. Journal of Advanced Concrete Technology. Time-Dependent Capacity of Large Scale Deep Beams under Sustained Loads. V 15-7, 314-327 (2017) 
17. K. Maekawa, A. Pimanmas, H. Okamura. Spon Press. Nonlinear Mechanics of Reinforced Concrete. (2003)

18. K. Maekawa, M. Soltani, T. Ishida, Y. Itoyama. Journal of Advanced Concrete Technology. Time-Dependent Space-Averaged Constitutive Modeling of Cracked Reinforced Concrete Subjected to Shrinkage and Sustained Loads. V 4-1, 193-207 (2006)

19. Z.P. Bažant, B.H. Oh. Matériaux et Construction. Crack Band Theory for Fracture of Concrete. V 16-3, 155-177 (1983)

20. X. An, K. Maekawa, H. Okamura. Proc. of JSCE. Numerical simulation of size effect in shear strength of RC beams. V 35-564, 297-316 (1997)

21. Ernst \& Sohn. fib Model Code for Concrete Structures 2010. (2013)

22. J.K. Wight, J. Mac Gregor. Pearson. Reinforced Concrete Mechanics and Design. E 6, (2005)

23. S.D. Adhikary, B. Li, K. Fujikake. ACI Structural Journal. Effects of High Loading Rate on Reinforced Concrete Beams (with Appendix). V 111-3, 651-660 (2014)

24. F.H. Wittman, P. E. Roelfstra, H. Mihashi. Materials and Structures. Influence of age of loading, water-cement ratio and rate of loading on fracture energy of concrete. V 20-2, 103-110 (1987)

25. F. Zhou. Doctoral Thesis, Lund Institute of Technology. Time-dependent crack growth and fracture in concrete. (1992) 